\title{
Improving Evidence-Based Practice education in healthcare courses: A Participatory Action Research multiple-case study
}

Kylie Murphy'; Tracey Parnell ${ }^{1}$; Rodney Pope ${ }^{1}$; Clarissa Hughes²; Jessica Biles ${ }^{2}$; Marguerite Bramble²; Simone OConnor ${ }^{1}$; Michael Curtin ${ }^{1}$; Lisa Speedie ${ }^{2}$; and Evan Plowman ${ }^{2}$

${ }^{1}$ School of Community Health, Charles Sturt University, Australia; ${ }^{2}$ School of Nursing Midwifery and Indigenous Health, Charles Sturt University, Australia.

\begin{abstract}
This paper synthesises the results of three participatory action research (PAR) studies undertaken to improve the integration of evidence-based practice (EBP) education in three undergraduate health courses at one Australian university: Bachelor of Nursing, Bachelor of Occupational Therapy, and Bachelor of Physiotherapy. The PAR process with interested academics uncovered a range of EBP education strengths and weaknesses in the three courses. Common themes were evident, which are likely to be applicable in other similar courses. Identified weaknesses included a lack of explicit teaching about the meaning, principles, steps, and importance of EBP, partly stemming from a lack of shared understanding. A relative lack of emphasis on certain EBP steps was also noted, particularly the first step of 'asking' questions. A lack of communication with workplace learning (WPL) supervisors about how to facilitate EBP was also noted, raising concerns about variable EBP-education quality across WPL settings. Opportunities for improvement were identified by academics in each course, across multiple subjects and year levels. In our experience, PAR has been a highly constructive approach to EBP curriculum improvement. We encourage consideration of a PAR approach for addressing similarly complex curriculum challenges.
\end{abstract}

Keywords: curriculum improvement; evidence-based practice; health care; undergraduate; action research; case study. 


\section{Introduction}

Among contemporary EBP scholars (e.g., Hitch \& Nicola-Richmond, 2017; Malik, McKenna \& Griffiths, 2017; Murphy et al., 2018), evidence-based practice (EBP) is considered to be a client-centred, collaborative process of enquiry and reasoning to facilitate defensible healthcare decisions. EBP requires healthcare practitioners to recognise uncertainty, seek relevant evidence to reduce that uncertainty, and judiciously incorporate that evidence in their decision-making. Based on the Sicily Statement on EBP (Dawes et al., 2005), contemporary scholars recommend that practitioners enact EBP in five steps: (1) Ask- Recognise situations of uncertainty, and articulate that uncertainty as answerable questions; (2) Acquire - Find the best evidence available, if there is any, on those questions; (3) Appraise - Judge that evidence for its applicability to the practitioner's situation and its validity/trustworthiness; (4) Apply Incorporate the evidence into their professional reasoning, along with their own and other clinicians' training and experience-based wisdom, their clients' values and preferences, and the practice context; and (5) Assess - Evaluate their reasoning processes and the outcomes of their decisions, and share their learning with colleagues if possible, to build practice-based evidence for the future. High quality EBP involves collaborative engagement with clients and colleagues (Drisko, 2017; Melnyk et al., 2010).

EBP is not routine for many practitioners, partly due to inadequate pre-service preparation (Rousseau \& Gunia, 2016; Saunders \& Vehviläinen-Julkunen, 2016). Integrating the five steps of EBP into the instructional and clinical experience of pre-service health practitioners is important for maximising their likelihood of engaging in EBP post-graduation (Brooke, Hvalič-Touzery, \& Skela-Savič, 2015; DeCleene Huber \& Nichols, 2015; Fiset, Graham, \& Davies, 2017; Hecht, Buhse, \& Meyer, 2016; Hitch \& Nicola-Richmond, 2017; Malik, McKenna, \& Griffiths, 2017; Saunders \& Vehviläinen-Julkunen, 2016). Students’ EBP confidence and pro-EBP attitudes are maximised when EBP skills are addressed in subjects beyond research-focused subjects, particularly in workplace learning (WPL) subjects (Murphy et al., 2018).

Research suggests that university curricula tend to predominately focus on acquiring and appraising research evidence - Steps 2 and 3 of EBP - without necessarily contextualising these processes as elements of EBP (Malik, McKenna, \& Griffiths, 2017). This is problematic because, unless the skills involved in Steps 1, 4 and 5 are also emphasised through explicit instruction, the value of teaching students Steps 2 and 3 might be limited and the potential of EBP to enhance healthcare might continue to be compromised.

Despite its importance, there is little published research on the question of how EBP education can be integrated across the non-research focused subjects of a course, and how such integration can be improved in an existing curriculum. Enhancing EBP integration is a complex curriculum-improvement challenge, not amenable to a top-down, simple, one-size- 
fits-all approach. Pre-existing strengths and weaknesses vary between courses. In addition, multiple stakeholders need to be involved in identifying, planning and implementing improvements, including academics who may not normally consider it to be their responsibility to teach EBP knowledge and skills.

This paper synthesises the results of three participatory action research (PAR) studies undertaken to improve the integration of EBP education in three undergraduate health courses at one Australian university.

Each PAR study aimed to:

- identify existing EBP education strengths in the course;

- identify weaknesses and opportunities to strengthen the EBP curriculum; and

- develop action plans that stakeholders felt were practical and worthwhile.

\section{The three courses}

\subsection{Bachelor of Nursing}

The 3-year Bachelor of Nursing (BN) course takes in approximately 450 students annually, across several campuses and online. This course satisfies the requirements for registration with the Nursing and Midwifery Board of Australia.

\subsection{Bachelor of Occupational Therapy}

The 4-year Bachelor of Occupational Therapy (BOT) course takes in approximately 80 students annually, across two campuses. This course satisfies the requirements for registration with the Occupational Therapy Board of Australia.

\subsection{Bachelor of Physiotherapy}

The 4-year Bachelor of Physiotherapy (BPT) course takes in approximately 130 students annually, across three campuses. This course satisfies the requirements for registration with the Physiotherapy Board of Australia.

\section{Participatory action research methodology}

We adopted an action research approach, which has been described by Reason and Bradbury (2006) as a purpose of enquiry where the aim is to acquire information with practical implications to solve specific, local, context-bound problems. Participatory action research (PAR) typically involves the researchers as stakeholders/contributors (Koshy, Koshy, \& Waterman, 2011). Many PAR models exist, most of which include 'action' and 'reflection' phases (Koshy et al., 2011). Few models focus on steps to ensure the initially planned actions 
are as promising as possible by engaging key stakeholders in the action-planning stage. Most models emphasise reflecting on the consequences of the planned actions. Our project involved stakeholders in data collection to inform an action plan to improve the EBP curriculum in each course. After sharing our literature-informed understanding of EBP with interested academics, we gathered and synthesised their insights and opinions regarding possible EBP education improvements in each course. Data was collected via individual interviews and/or focus groups. Draft action plans were proposed to the teams for further feedback and refinement.

\section{Multiple case study methodology}

Stake (2006) defines the multiple case study approach as studying multiple cases simultaneously or sequentially as a way of generating a broader appreciation of a particular issue. For us, the 'issue' was the challenge of improving undergraduate EBP curricula. As advised by Crowe et al. (2011), in this multiple case study, data collection was flexible enough to allow a detailed examination of the issue in each case, but broadly comparable to enable consideration of emerging similarities and differences in cross-case comparisons.

\section{What EBP education was already occurring?}

\subsection{Bachelor of Nursing}

In the BN, EBP was focal in a standalone research-focused subject in Year 3 and 'touched on' in other subjects. Particular academics taught and integrated EBP into their subjects very well. Generally, Steps 1 to 3 were believed to be covered in course work, and Steps 4 and 5 in WPL subjects; but this was often not explicitly named as EBP. In simulation labs, students practiced various steps of EBP; but not all steps, and they were rarely identified as EBP.

\subsection{Bachelor of Occupational Therapy}

A number of subjects in the BOT addressed EBP, and some academics were able to articulate EBP well. A multi-disciplinary research-focused subject in Year 2 identified the five steps of EBP, and links to these concepts were made in another Year 2 subject and in Year 3 journal clubs. Skills to acquire and appraise research evidence (Steps 2 and 3) were explicitly taught and assessed, including in a Year 2 assignment called 'Research Evidence in Professional Practice'. Oral viva assessments were conducted in Year 2 and 3 to give students practice in thinking dynamically and flexibly and articulating their decision-making. Some academics were particularly passionate about encouraging students to progress from black-and-white thinking, stimulating curiosity, and generally improving the EBP curriculum. 


\subsection{Bachelor of Physiotherapy}

The BPT included the above-mentioned research-focused subject in Year 2, which covers the five steps of EBP. EBP education continued across the course, including in assessment tasks. BPT academics took pride in the way they modelled EBP to students, though they did not always name it as EBP. In Year 3, journal club sessions addressed some EBP skills, though not explicitly. There was also an awareness by academics that traditional EBP tends to assume a Western view of healthcare and knowledge generation, to the exclusion of other ways of knowing based on, for example, Indigenous and Chinese cultures.

\subsection{Common themes}

All three courses started with significant strengths: EBP already had a firm place in the curricula; some teaching staff were already quite knowledgeable and passionate about EBP; and a critical mass of staff in each teaching team showed enthusiasm towards finding ways to increase the effectiveness of the EBP curriculum.

\section{What weaknesses and opportunities were identified?}

\subsection{Bachelor of Nursing}

The BN academics agreed that EBP should not be consigned to a standalone subject delivered in Year 3. Based on the backgrounds and characteristics of the academics, variability was noted between subjects in terms of how well EBP was articulated. EBP steps were rarely labelled as such or explained in terms of their interrelatedness with the other steps. There was a perceived need for greater consistency between subjects/academics through more explicit reference to the principles and processes of EBP in subject documentation.

\subsection{Bachelor of Occupational Therapy}

The BOT academics identified inconsistencies in the meanings they attributed to EBP. They felt that, when EBP was covered, the focus was too much on research evidence, to the exclusion of other types of evidence. They also felt students needed more direct instruction and opportunities to practice the full range of skills involved in EBP. In particular, it was felt that more could be done to foster a spirit of enquiry (Step 1). The focus seemed to be on Steps 2 and 3, with academics performing Step 1 for the students. EBP seemed to be mainly addressed via assessment tasks; not so much via explicit instruction or modelling. There was a perceived lack of connection by students between client-centred practice and EBP. There was also a perceived blind-spot in relation to EBP in WPL; unchecked assumptions were perhaps made about what students learn during their placements. The academics suspected students' research-focused learning was disconnected from their clinical subjects and WPL experiences, with EBP possibly seen as an optional add-on. 


\subsection{Bachelor of Physiotherapy}

The BPT academics felt that although their existing EBP curriculum was reasonably comprehensive, EBP was not taught as explicitly as it could be. It was also felt that some students' and WPL supervisors' concept of evidence was too restrictive: The potential of EBP to enhance healthcare would be greater if evidence was considered more broadly than just published research evidence. It was recognised that, in Years 3 and 4, Steps 1 to 3 were 'assumed knowledge' and not routinely revisited or reinforced; the focus shifted to Steps 4 and 5. However, these skills were not usually framed as EBP and it was acknowledged that students might not be conducting Steps 1 to 3 as assumed. Particular concerns were raised in relation to students' learning of Step 1 skills. First, BPT academics noted a strong tendency to ask questions about intervention effectiveness; not about outcome measures, diagnostic accuracy, prognostic predictions, patient lived experiences, etc. Second, students were given little guidance in relation to formulating clinical questions, particularly when PICO (population, intervention, comparison, outcome) question structures were inapplicable. Third, questions set by the academics usually called for research evidence rather than other forms of information. In relation to Step 4, the EBP curriculum was seen to need greater emphasis on individual cultural expectations, values, and sensitivities.

\subsection{Common themes}

The three teaching teams identified that their conceptualisations of EBP varied. Most steps of EBP were addressed in the respective curricula, but often not explicitly and holistically. Steps 1 to 5 were rarely addressed as a full process in relation to a particular clinical scenario. Instead, EBP skills were taught in a piecemeal fashion with the expectation that students would naturally join them together in their professional practice. There was a tendency to focus on Steps 2 and 3, somewhat ignoring the skills involved in Step 1. Finally, it was suspected that EBP knowledge and skills taught within the courses were not necessarily being reinforced or practiced during students’ WPL experiences.

\section{What improvements were considered practical and worthwhile?}

\subsection{Bachelor of Nursing}

BN academics felt that a standard definition of EBP (incorporating the five steps) should be promoted so that all BN team members can instruct, model, and assess EBP in a consistent and explicit way. It was also agreed that EBP should be introduced in Year 1, explicating all five steps, and that the skills required for each step should be progressively developed in subsequent subjects. It was felt EBP steps should be labelled explicitly 'as they happen', including in theoretical examples, simulation labs, and WPL pre- and post-briefing. There was a perceived need to work more closely with WPL staff, including through improved 
guidelines and documentation, to highlight the importance of developing students' EBP skills. The academics believed the overarching aim should be to ensure their students can explain why EBP is important for all nurses - how it relates to lifelong learning, patientcentred practice, and care improvement - and why it should not be seen as the preserve of senior clinicians and those who have a special interest in research.

\subsection{Bachelor of Occupational Therapy}

The BOT academics felt that existing problem-based and scenario-based learning activities provided untapped opportunities for practicing EBP skills. For example, students could be given opportunities to practice translating their uncertainty into questions; explaining relevant research as if in response to a client asking a question; and describing how they would apply research evidence in a clinical scenario and explaining their reasoning (e.g., considering the context, client needs, their own skills). To assist students, videos could be shown of therapists explicating the reasoning process. To address unhelpful misconceptions about EBP, the academics felt they should frame client-centred practice as part of EBP (particularly Steps 1 and 4); not as separate from it. They felt that orientation training for new teaching staff and WPL supervisors should include a standard definition of EBP; the importance of using common terminology when discussing EBP (including the five steps); teaching and assessing all EBP skills directly and explicitly; and, wherever possible, reinforcing EBP principles (client-centred, enquiring, collaborative).

\subsection{Bachelor of Physiotherapy}

The BPT staff felt that EBP should be introduced more explicitly in Year 1 of the course, with relevant concepts and skills being continually reinforced and extended in subsequent years, using a template approach. It was also suggested that evidence should be defined more broadly than just research evidence. For example, ascertaining and respecting clients' personal priorities and cultural beliefs is as important as acquiring research evidence. In order for EBP to be better signposted for students, upskilling of staff involved in facilitating problem-based learning (PBL) and WPL was considered important: All parties need a common understanding of what EBP means and how to model it. Carefully designed assessment rubrics were also believed to be important for ensuring that staff and students understand what high quality EBP looks like. It was also felt that students should be given more opportunities to practice and receive feedback on their EBP skills in authentic contexts, including Step 1. For example, students should be given feedback on their attempts to structure clinical questions of various kinds during PBL and WPL. In relation to interventionfocused questions, it was noted that students should be taught that lack of evidence does not equate to lack of effectiveness. 


\subsection{Common themes}

In discussing possible actions, there was a common focus on establishing a consistent understanding of EBP. There were calls for EBP to be operationally defined in subject documentation, including for PBL and WPL staff. The need for explicit instruction, demonstration, and assessment of EBP skills was a common theme. Academics in all three teams felt it was important to label when students were engaging in EBP and provide feedback on how they might improve their EBP skills. All EBP steps were considered important to teach, including Step 1. There was also agreement that all EBP steps should be introduced in Year 1 and progressively developed throughout each course.

\section{Discussion and Conclusion}

The PAR process uncovered a range of EBP education strengths and weaknesses in the three courses. Common themes were evident, which are likely to be applicable in other similar undergraduate healthcare courses. All three courses already had strong references to EBP. Another common strength was the interest and good will shown by the teaching teams towards the project. Identified weaknesses included a lack of explicit teaching about the meaning, principles, steps, and importance of EBP, partly owing to a lack of shared understanding of EBP. A relative lack of emphasis on certain EBP steps was also noted; as was a lack of communication with WPL supervisors about how to facilitate EBP, raising concerns about variable EBP-education quality across WPL settings. Opportunities for improvement were identified by academics in each course, across multiple subjects and years.

At the time of writing, the process of consultation, feedback, and refinement of action-plans is still ongoing. However, so far, agreed improvements tend to be aimed at promoting a shared and explicit understanding of EBP across all academics/subjects in each course, including in WPL. Some agreed actions have already been enacted. Further changes will be made to subject outlines and assessment tasks over coming months.

While major common themes arose, slight differences in focus were evident in the three case studies. These differences reflect different baseline strengths and weaknesses, disciplinary peculiarities, and different views of the academics responsible for building and maintaining the respective courses. These differences were respected in the PAR approach adopted in this project. In all three cases, academics generously engaged in the PAR process. The collaboration and knowledge-sharing engendered in this process are benefits associated with formal Communities of Practice (Gehrke \& Kezae, 2017).

PAR aims to involve, empower, and improve (Reason \& Bradbury, 2006). In our experience, PAR has been a highly constructive approach to EBP curriculum improvement. Clear benefits are already evident, including heightened interest in, and a deeper understanding of, EBP education among the staff in each course team, and a genuine commitment to numerous 
identified improvements. We encourage consideration of a PAR approach for addressing similarly complex curriculum challenges, such as improving students' cultural competency, academic literacy, and interprofessional practice. Systematic, respectful, collaborative approaches to curriculum improvement, such as PAR, are time- and effort-intensive, but promise better outcomes than short-cut, tick-box approaches.

\section{References}

Brooke, J., Hvalič-Touzery, S., \& Skela-Savič, B. (2015). Student nurse perceptions on evidence-based practice and research: An exploratory research study involving students from the University of Greenwich, England and the Faculty of Health Care Jesenice, Slovenia. Nurse education today, 35(7), 6-11.

Crowe, S., Cresswell, K., Robertson, A., Huby, G., Avery, A., \& Sheikh, A. (2011). The case study approach. BMC Medical Research Methodology, 11, 100-100.

Dawes, M., Summerskill, W., Glasziou, P., Cartabellotta, A., Martin, J., Hopayian, K., . . . Osborne, J. (2005). Sicily statement on evidence-based practice. BMC Medical Education, 5(1).

DeCleene Huber, K. E., \& Nichols, A. (2015). The correlation between confidence and knowledge of evidence-based practice among occupational therapy students. Open Journal of Occupational Therapy, 3(1).

Drisko, J. (2017). Active collaboration with clients: An underemphasized but vital part of Evidence-Based Practice. Social Work, 62(2), 114-121.

Fiset, V., Graham, I., \& Davies, B. (2017). Evidence-Based Practice in clinical nursing education: A scoping review. J. Nurs. Educ., 56, 534-541.

Gehrke, S. \& Kezar, A. (2017). The roles of STEM faculties Communities of Practice in institutional and departmental reform in higher education. American Educational Research Journal, 54(5), 803-833.

Hecht, L., Buhse, S., \& Meyer, G. (2016). Effectiveness of training in evidence-based medicine skills for healthcare professionals: A systematic review. BMC medical education, 16(1), 103-119.

Hitch, D., \& Nicola-Richmond, K. (2017). Instructional practices for evidence-based practice with pre-registration allied health students: A review of recent research and developments. Advances in Health Sciences Education, 22(4), 1031-1045.

Koshy, E., Koshy, V., \& Waterman, H. (2011). Action Research in Healthcare. London: SAGE Publications Ltd.

Malik, G., McKenna, L., \& Griffiths, D. (2017). Using pedagogical approaches to influence evidence-based practice integration - processes and recommendations: Findings from a grounded theory study. Journal of Advanced Nursing, 73(4), 883-893.

Melnyk, B., Fineout-Overholt, E., Stillwell, S., \& Williamson, K. (2010). Evidence-based practice: Step by Step: The seven steps of evidence-based practice. American Journal of Nursing, 110(1), 51-53. 
Murphy, K., Guisard, Y., Curtin, M., Thomas, C., Crawford, R., \& Biles, J. (2018). Impact of the learning context on undergraduate healthcare students' Evidence-Based Practice confidence and attitudes. Health Education in Practice: Journal of Research for Professional Learning, 1(1), 32-50.

Reason, P., \& Bradbury, H. (2006). Handbook of action research (Concise paperback edition. ed.). Thousand Oaks, California: Sage Publications.

Rousseau, D. M., \& Gunia, B. C. (2016). Evidence-Based Practice: The psychology of EBP implementation. Annu Rev Psychol, 67, 667-692.

Saunders, H., \& Vehviläinen-Julkunen, K. (2016). The state of readiness for evidence-based practice among nurses: An integrative review. International Journal of Nursing Studies, 56, 128-140.

Stake, R. E. (2006). Multiple case study analysis. The Guilford Press, New York. 